\title{
About a Dilemma in the Telecommunications Sector: Virtual Operators or Low-cost Operators?
}

\author{
Olivier Lefebvre ${ }^{1}$
}

${ }^{1}$ Olivier Lefebvre, Consultant, Paris, France.

\begin{tabular}{l}
\hline Article info \\
\hline Received April 30 th 2019 \\
\hline Keywords \\
Bertrand competition \\
Bertrand paradox \\
Differentiated products \\
Saturated markets \\
Virtual operator
\end{tabular}

Corresponding author

Olivier Lefebvre

Olivier Lefebvre Consultant

4 rue Rollin 75005 Paris France

E-mail : o.lefebvreparis05@orange.fr
ABSTRACT. A virtual operator is fragile when it is in competition with other virtual operators. This is explained by the "Bertrand paradox": when firms sell products not differentiated (or not enough differentiated) a price war has terrible consequences (the profits tend to zero). But it is worse if there is a price war between the operators with a network. It occurred in France during the period $2012-2018$. The entrant Free triggered a price war. The reaction of the incumbents was to create low-cost operators which were their branches. The only virtual operator with a large size, Virgin Mobile, was "bought and closed down" by the incumbent SFR. It suffered too much because of the incumbents decreasing their prices and the low-cost operators, both. It lost many customers. One proposes a model to explain why the "buy and close down" of Virgin Mobile was profitable (and chosen) in these conditions. The method used is Bertrand competition.

Also, the "buy and close down" which is profitable is a criterium for products which are not enough differentiated. A few examples are given.

The aims of the paper are two:

- To study how works a price war in telecommunications.

- More generally, the possibility of profitable "buy and close down" allows to propose a criterium for saturated markets. Even, the criterium could be used to build software (to test if a market is saturated or not). The rival models which are presented in the literature are commented.

\section{Introduction.}

In many countries there are Mobile Virtual Network Operators. They have no network [1]. They buy traffic from operators with a network [2]. But there are also Low-Cost Operators: they are branches of operators selling the standard service, as virtual operators, while the operator itself sells the sophisticated service. The topic which is dealt with in this paper is the coexistence of virtual operators and low-cost operators.

Virtual operators are fragile, if they have low cost operators as competitors. The reason is the following: in case of price war, a virtual operator loses its customers and goes bankrupt. At the opposite, a low cost operator can decrease its price without unbearable loss, because: (1) its cost is less than the virtual operator, and (2) when it decreases its price, it loses less profit, because it cannibalizes the customers of the operator itself (when the operator loses a customer who is recovered by the low cost operator, it makes less profit, but its profit is not reduced to 0 ). 
This allows to understand in a better way the story of the telecommunications sector in France, between 2012 and 2018. At the start, there were three mobile operators, Orange, SFR and Bouygues Telecom. Then the regulator decided to allow an entry: the entrant was Free. Free triggered a longlasting price war to get a market share. It sold the standard service at a low price. It succeeded. The incumbents reacted in this way: they created low-cost operators which were their branches. The goal was to thwart Free on its terrain: to sell the standard service to customers wanting to make economies. The low-cost operators were Sosh for Orange, Red for SFR and B and You for Bouygues Telecom. The outcome was a spectacular decrease of prices in France: the average of the amount of the monthly invoice decreased from 26 Euros to 16 Euros (it is the average of pre-paid and post-paid). Concerning the virtual operators, there were several but one was remarkable, Virgin Mobile [3]. It was very innovative:

- It reached nearly two million of customers

- It was the first to offer very cheap SMSs (Short Messaging System)

- It was the first to offer "SIM ${ }^{1}$ only" formulas (purchase without obligation, no terminal provided, only the SIM card is provided)

- It was the first to offer unlimited calls

- It was the first to offer "quadruple play" (telephone, television and Internet thanks to a "box" and mobile telephony).

It became a "full MVNO". That is to say, it owned some segments of networks, was able to buy traffic from several sellers (it is useful to lower the cost of the traffic which is purchased). It sold its own SIM cards. It owned a brand. Even, it owned a few stores.

But the price war triggered loss of customers. Because of the competition with the low-cost operators, its profit decreased. Finally, Virgin Mobile was owned by an incumbent, its host operator SFR ${ }^{2}$. Later the brand Virgin Mobile disappeared and the customers were transferred to Red and SFR.

It seems that there are two kinds of situations:

- Either the prices decrease because of virtual operators which have a large size, are stable, have a brand and become "full MVNOs". It is the case of Germany, Denmark, Netherlands ...

- Either the prices decrease because of a price war. Low-cost operators are created. The main virtual operators are purchased. It is the case of France.

What is interesting in the story of the purchase of Virgin Mobile by SFR is that it was closed down. It is what we call "buy and close down": an asset is bought then closed down. In general, the asset which is bought is used: it is a "buy and manage". In this paper one explains the profitability of "buy and close down", which exists sometimes, by game theory and the "Bertrand paradox". When the utilities of the consumers have nearly the same values, concerning several products, it is easy to catch all the market by decreasing one's own price. Finally, the prices are very low and this explains that the "buy and close down" can be profitable.

In this paper there are two parts:

- In the first part one studies the "Bertrand paradox" and the reasons why the "buy and close down" can be profitable. The method comes from game theory: it is Bertrand competition. This method is described by Jean Tirole [4]. However, one uses this tool from game theory in a particular way: (1) one deduces the demand from the consumers' utilities. Details on this method are given in the book written by the author of this article "Game theory and the stakes in the telecommunications industry" [5], and (2) more than two players are considered (indeed, three). Examples of "buy and close down" are presented. One can present examples which are tractable.

- In the second part one models a telecommunications sector with two competitors (operators with networks) and virtual operators and low-cost operators. One demonstrates that to "buy and close down" a virtual operator is profitable. Indeed, it is profitable when one passes from Nash equilibrium to another Nash equilibrium, or when there is a price war. In France, there was a price war when Virgin Mobile was "bought and closed down".

\footnotetext{
${ }^{1}$ SIM : Subscriber Identity Module.

${ }^{2}$ Indeed, Virgin Mobile was bought by Numericable, a cable operator. Then Numericable bought SFR. At this time SFR owned Virgin Mobile.
} 


\section{Materials and methods.}

We give details on the Bertrand paradox and particular cases. Also, an example is the competition between a virtual operator and a low-cost operator.

In the Bertrand paradox two firms $\mathrm{E}_{1}$ and $\mathrm{E}_{2}$ sell two different products. They choose their prices. But the products are not differentiated. That is to say, for any consumer the utility of the product of $E_{1}, u_{1}$ is equal to the utility of the product of $\mathrm{E}_{2}, \mathrm{u}_{2}$. If $\mathrm{u}_{1}=\mathrm{u}_{2}$ all the density is on the bisector (Fig. 1).

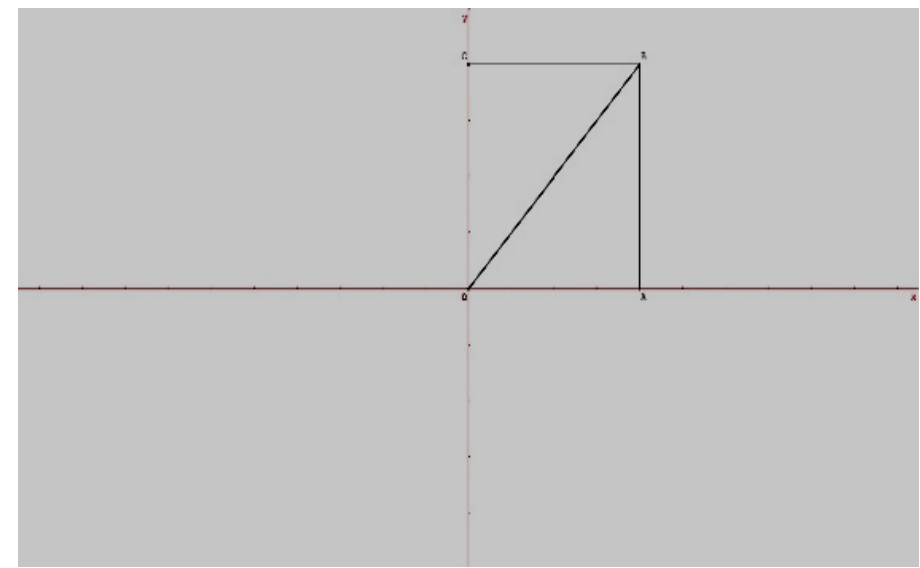

Figure 1: in the Bertrand paradox all the density of the utilities is on the bisector.

It is easy to demonstrate that at the equilibrium every firm makes no profit. The Nash equilibrium corresponds to $\mathrm{p}_{1}=\mathrm{p}_{2}=0, \mathrm{P}_{1}=\mathrm{P}_{2}=0$. For reasons of symmetry the equilibrium price is $\mathrm{p}_{1}=\mathrm{p}_{2}=\mathrm{p}_{0}$. If $\mathrm{p}_{0}>0$, one of the firms can choose $\mathrm{p}_{0}-\varepsilon\left(\varepsilon>0\right.$ and small) and catch $\mathrm{D}\left(\mathrm{p}_{0}\right) / 2$. Its profit increases. Therefore, the only value possible for $\mathrm{p}_{0}$ is 0 .

Now, if $\mathrm{E}_{1}$ buys $\mathrm{E}_{2}$ and closes down it, it makes the monopoly profit $\mathrm{P}_{\mathrm{m}}, \mathrm{P}_{\mathrm{m}}>0$. Therefore, the "buy and close down" is profitable. Before the purchase the profit of $E_{1}$ was 0 and the profit of $E_{2}, 0$. The profit of $\mathrm{E}_{1} \mathrm{P}_{\mathrm{m}}$ is more than $0+0=0$ and the operation is profitable. $\mathrm{E}_{1}$ can pay for an amount $\varepsilon^{\prime}\left(\varepsilon^{\prime}>\right.$ 0 and small) to buy $E_{2}$ and makes a gain since $P_{m}-\varepsilon^{\prime}>0$. It could also keep $E_{2}$ and the outcome would be the same. In this case the outcome of "buy and close down" and "buy and manage" is the same.

In general, when there are two players, the "buy and manage" allows more gain than the "buy and close down". The argument is that of the replication of the choice: when the buyer manages the asset he bought, he can replicate the choice of "buy and close down" (which corresponds to $\mathrm{p}_{2}$ maximal and $\mathrm{p}_{1}$ allowing the maximal profit, $\mathrm{p}_{2}$ being given). Then he maximizes his profit. Therefore, in practice, one cannot see a "buy and close down" when there are two firms.

What are the examples of "buy and close down" which are chosen, because they are profitable (and more profitable than "buy and manage")?

Indeed, they are rare and discreetly conducted by managers, because to destroy an asset (machines, brand etc.) is scandalous. A famous example is the Brazilian coffee burnt in the locomotives at the time of the Great Depression. Another example is the Garot law recently voted in France, imposing to the supermarkets to give their unsold food to associations, instead of destroying it. The associations distribute the food to poor people who in any case would not have bought the food (therefore the supermarkets do not lose any demand). It shows that destruction of goods is scandalous. However, one can quote a recent example in France. In 2017, in Docelles, a village, the firm UPM (United Paper Mills), a paper producer, closed a plant. At this time, members of the staff during a night, destroyed the machines used to produce papers (big cylinders) 3 . So they could not be sold to competitors who would have used them. It raised a scandal [6]. However, in this paper one postulates that the managers know what they do. UPM has paid for money (the loss which is the consequence of the machines which are not sold) to get less competition, when the products are not differentiated enough. In this case, the operation is profitable (it is demonstrated thanks to Bertrand paradox). Even, the "buy and close down" which is profitable is a criterium for a market with products not enough differentiated.

\footnotetext{
${ }^{3}$ The managers acted during the night, not because the destruction of the machines was illegal, but because it was scandalous.
} 
To know if a "buy and close down" is profitable, one compares two states. First, there is Nash equilibrium with $n$ players. If $E_{1}$ is the purchaser and $E_{2}$ the purchased, their profits are $P_{1}$ and $P_{2}$. After the purchase, $E_{2}$ is closed down, there is a Nash equilibrium with $n-1$ players. The profit of $E_{1}$ is $\mathrm{P}_{1}$. The "buy and close down" is profitable if $\mathrm{P}_{1}>\mathrm{P}_{1}+\mathrm{P}_{2}$. If $\mathrm{E}_{1}$ keeps $\mathrm{E}_{2}$, there is also a Nash equilibrium with $n-1$ players, but $E_{1}$ maximizes the sum of the profits of $E_{1}$ and $E_{2}$ (given the choices of the competitors). Suppose its profit is $\mathrm{P}$ " ${ }_{1}$. The "buy and manage" is profitable if $\mathrm{P}{ }_{1}>\mathrm{P}_{1}+\mathrm{P}_{2}$. When there are two players the "buy and manage" is always profitable and more profitable than the "buy and close down". When there are at least three players there are two cases:

The "buy and manage" is more profitable than the "buy and close down". If the "buy and manage" is profitable it should be chosen.

The "buy and close down" is more profitable than the "buy and manage". If the "buy and close down" is profitable, it should be chosen. It is the only example of "buy and close down" which can be observed in the reality (the case of UPM at Docelles).

Indeed, in the case of Virgin Mobile and UPM at Docelles, it was not a "buy and close down", but a "close down" since the firms already owned the assets (their branches). The "close down" was preferred to demerging (and to keep the asset).

But the "close down" depends on the same conditions than the "buy and close down". And the "keep and manage" depends on the same conditions than the "buy and manage". We shall return on this topic in the following chapter.

Now we describe a tractable example of "buy and close down" which is profitable.

In this example the density of utilities is distributed homogeneously on the bisector in the plane $\mathrm{u}_{3}=1 / 2$ (Fig. 2).

The Bertrand paradox applies. At the Nash equilibrium with three players, $\mathrm{p}_{1}=\mathrm{p}_{2}=0, \mathrm{P}_{1}=\mathrm{P}_{2}=\mathrm{O}$, $\mathrm{p}_{3}=1 / 4, \mathrm{P}_{3}=1 / 16$. Now one supposes that $\mathrm{E}_{3}$ buys $\mathrm{E}_{2}$ for a price equal to $\varepsilon(\varepsilon>0$, small). First, the "buy and close down" is profitable. At the new equilibrium, $\mathrm{p}_{1}=\mathrm{p}_{3}=1 / 2, \mathrm{P}_{1}=\mathrm{P}_{3}=1 / 4$. The "buy and close down" is profitable: $1 / 4>1 / 16+0=1 / 16$. But also, the "buy and close down" is chosen by $\mathrm{E}_{3}$ because it gains more than choosing "buy and manage". Indeed, the "buy and manage" triggers neither gain neither loss. The profit $\mathrm{P}_{3}$ remains $1 / 4$. Therefore, $\mathrm{E}_{3}$ should prefer "buy and close down".

Why "buy and close down" is chosen appears. When $E_{2}$ is closed the response of $E_{1}$ is to increase its price (because it is as if $\mathrm{E}_{1}$ has chosen the maximal price, and prices are strategic complements). After that, $\mathrm{E}_{3}$ increases its price (since prices are strategic complements). Finally, the low prices because of products which are not differentiated enough, no more exist.

One can explain the case of UPM at Docelles. When a branch is closed, there is a competitor less (since the machines are not sold, they are destroyed). One of the competitors responds by increasing its price, then another does the same thing (because the prices are strategic complements). There are no more the low prices because of the products which were not enough differentiated. The profits increase.

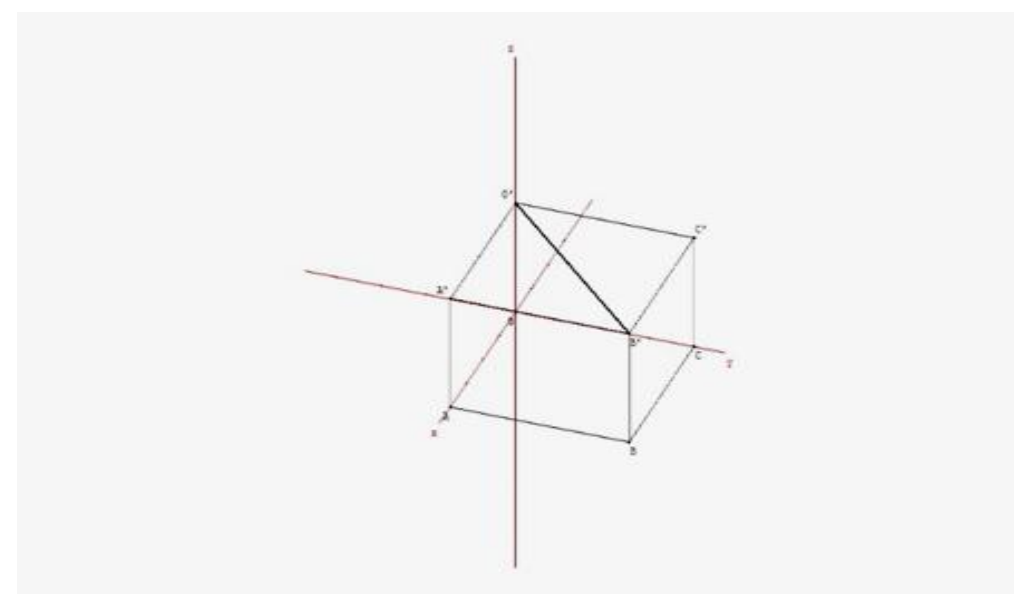

Figure 2: the density of utility is on the bisector, in the plane $u_{3}=1 / 2$ 
Now we use the method (Bertrand competition, the demands being deduced from the utilities) to model the competition between virtual operators and low-cost operators.

One supposes two operators with networks $E_{1}$ and $E_{2}$ selling sophisticated packages. There is also one virtual operator ( $E_{1}$ being the host operator) or there are two $\left(E_{1}\right.$ and $E_{2}$ being the host operators). It is simpler to reason on one virtual operator, and the results are the same (under some conditions). For every consumer there are three utilities, $\mathrm{u}_{1}, \mathrm{u}_{2}$ and $\mathrm{u}_{3}$ corresponding to the services sold by $\mathrm{E}_{1}, \mathrm{E}_{2}$ and to the standard service. The price $\mathrm{p}_{3}$ of the standard service remains fixed. It is a price not too low (since a virtual operator has a high cost $c+m$, c being the cost of the host operator and $m$ the margin when it sells traffic) and not too high, to attract customers. If there are two virtual operators there is no Nash equilibrium. The Bertrand paradox applies (the two virtual operators sell the same service, the standard service). One knows that if it triggers a price war, the two will probably go to bankrupt after some time. So, nothing occurs. The price remains $\mathrm{p}_{3}$.

It is the same reasoning after the entry of a low-cost operator (or two). A low-cost operator can trigger a price war against a virtual operator and win but this time the objection is the regulator. Finally, the price of the standard service remains the same when there is a virtual operator (or there are two) and when there is also a low-cost operator (or there are two).

One demonstrates that the "buy and close down" is profitable in two cases: (1) one passes from a Nash equilibrium (with one virtual operator and one low-cost operator) to a new one (after the "buy and close down") and (2) price war.

One passes from a Nash equilibrium to another one.

In a plane $\mathrm{O} \mathrm{u}_{1} \mathrm{u}_{2}$ one represents the demand for $\mathrm{E}_{1}$ (and $\mathrm{E}_{2}$ ). On the figure 3 in the zone hatched vertically there are only customers for $\mathrm{E}_{1}$. In the zone hatched horizontally there are customers for $\mathrm{E}_{1}$ and for the virtual operator (one on two) and the low-cost operator (one on two). This is explained by this inequality: $\mathrm{u}_{3} \leq \operatorname{Inf}\left(\mathrm{u}_{1}, \mathrm{u}_{2}\right)$. Indeed, even the lowest evaluation of the sophisticated package by a customer is more than the evaluation of the standard service (by the same customer) since the standard service is "comprised" in the sophisticated package.

Now, if the figure 3 represents the Nash equilibrium before the "buy and close down" a small $\mathrm{dp}_{1}$ triggers $\mathrm{dP}_{1}=0$. Customers are lost in a little strip and also some in the zone hatched horizontally, and customers in the zone hatched vertically remain, paying a little more money $\left(\mathrm{p}_{1}+\mathrm{dp}_{1}\right)$. The two exactly compensate each other. After the "buy and close down" the loss triggered because of the customers lost by $E_{1}$ and choosing the virtual operator (one on two) and the low-cost operator (one on two) is less. It is because a customer choosing the virtual operator before the "buy and close down" chooses now the low-cost operator and the profit is more for $\mathrm{E}_{1}$ (the margin $\mathrm{m}$ plus the profit of the virtual operator instead of the margin $\mathrm{m}$ ). Therefore, $\mathrm{dP}_{1}>0$. Concerning $\mathrm{E}_{2}$ a small dp triggers $\mathrm{dP}_{2}=$ 0 (there is no change). Or if $\mathrm{E}_{2}$ is host operator for a virtual operator and has a low-cost operator, $\mathrm{dP}_{2}>0$ after the "buy and close down". Finally, if one supposes that the prices are strategic complements and that the equilibrium is stable, the two prices $\mathrm{p}_{1}$ and $\mathrm{p}_{2}$ increase. The "buy and close down" is profitable. When $\mathrm{E}_{1}$ buys and closes down the virtual operator it hosts, there is a new Nash equilibrium and its profit increases.

The direct effect is neither a gain neither a loss: the price paid for by $E_{1}$ is compensated by the profit of the virtual operator. And the strategic effect is an increase of the profit $\mathrm{P}_{1}$.

If there are two low-cost operators there are conditions. The operator $\mathrm{E}_{1}$ can retain the customers of the virtual operator, if it offers little advantages (like rebates). The direct effect for $\mathrm{E}_{1}$ is neither a gain neither a loss. Otherwise the direct effect is a loss and it is not sure that the "buy and close down" is profitable. Also, only if it retains its customers choosing the standard service, offering little advantages (so they go from the operator itself to the low-cost operator which is its branch), the reasoning on $\mathrm{dp}_{1}$ $>0$ triggering $\mathrm{dP}_{1}>0$, holds. The reasoning on $\mathrm{dp}_{2}>0$ triggering $\mathrm{dP}_{2}>0$ holds. Thus, the "buy and close down" is profitable when there are two low-cost operators if $\mathrm{E}_{1}$ retains its customers.

Price war.

The model explains why during a price war a virtual operator loses its customers. Suppose that $\mathrm{p}_{1}$ and $\mathrm{p}_{2}$ decrease (price war) while $\mathrm{p}_{3}$ is fixed. When there is a $\mathrm{dp}_{1}<0, \mathrm{E}_{1}$ wins money by catching four kinds of customers: (1) those who did not buy any service (2) some customers of $E_{2}$ (3) customers of the virtual operator (4) customers of the low-cost operator. The customers of the kinds (3) and (4) are in the zone hatched horizontally. In the cases (1) and (2), $E_{1}$ wins its margin. In the case (3) it wins 
money because its margin is more than the margin $m$ of the sale of traffic. In the case (4), it wins money because the margin of $\mathrm{E}_{1}$ is more than the margin of the low-cost operator (even if there is a price war, the price $\mathrm{p}_{3}$ is low compared to $\mathrm{p}_{1}$ ). The operator $\mathrm{E}_{1}$ cannibalizes itself, catching customers from its branch the low-cost operator. Concerning $\mathrm{E}_{2}$ when there is $\mathrm{dp}_{2}<0$, it wins its margin in all the cases. But the most interesting is what happens to the virtual operator. It loses its customers because of the price war, and loses half of its customers when the low-cost operator is created. Finally, it accepts to be purchased at a low price, and this explains that the "buy and close down" is chosen.

After the "buy and close down" the price $\mathrm{p}_{3}$ remains the same. The "buy and close down" has to be approved by the regulator. In general, the condition is that the price will not increase.

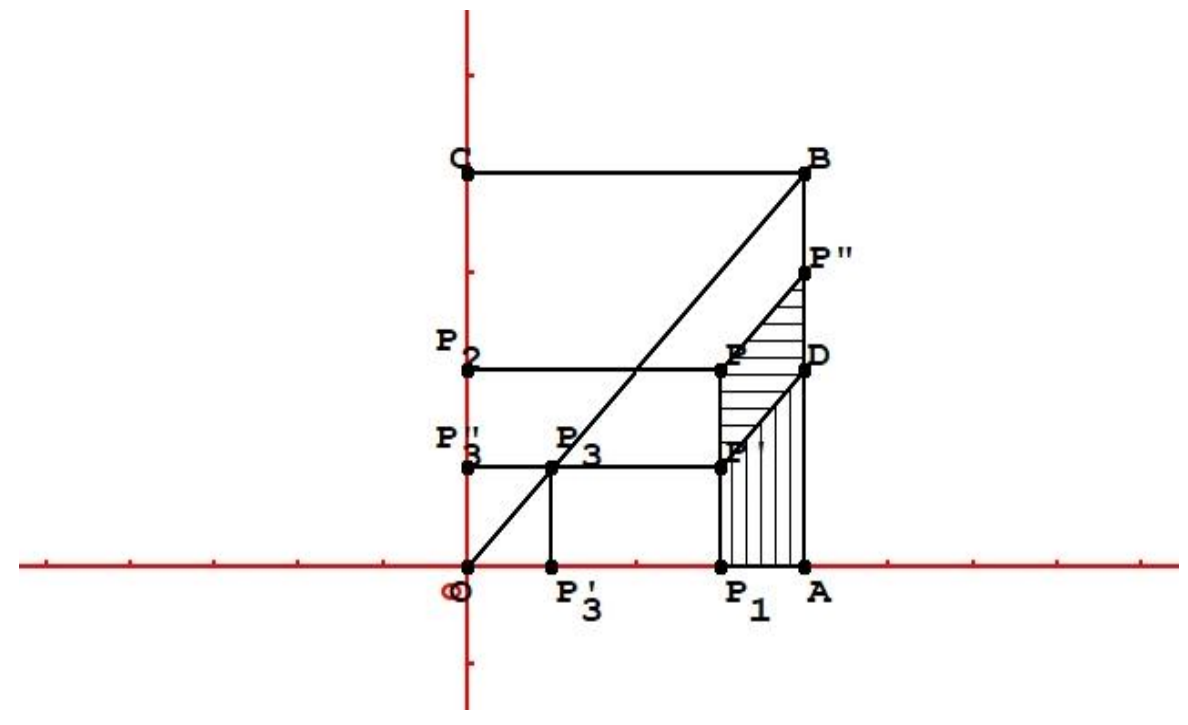

Figure 3: The demand $\mathrm{D}_{1}$ is shown. The prices $\mathrm{p}_{1}, \mathrm{p}_{2}, \mathrm{p}_{3}$ correspond to the points $\mathrm{P}_{1}, \mathrm{P}_{2}$ and $\mathrm{P}_{3}$ and $\mathrm{P}{ }_{3}$. The axes correspond to $\mathrm{u}_{1}\left(\right.$ and $\left.\mathrm{p}_{1}\right)$ in abscissas and $\mathrm{u}_{2}\left(\right.$ and $\mathrm{p}_{2}$ ) in ordinates.

\section{Results and discussion.}

One has shown that when how an asset is managed is considered, the decision tree has not two branches (to buy or not to buy, or to sell or not to sell) but three. If the asset is not owned the three possible decisions are: no purchase, to buy and manage and to buy and close down. If the asset is owned the three possible decisions are: to keep, to demerge and to close down. The decision which is taken allows the maximal profit. In this chapter we give more details on this topic and propose the criterion "buy and close down is profitable" as a general criterion for markets with too many kinds of products. Then we compare with the existing methods (to detect markets saturated by too many kinds of products). Also, we apply the criterion to virtual operators and low-cost operators.

Now we describe the decision tree and its three branches. Suppose the profit of the purchaser $E_{1}$ is $\mathrm{P}_{1}(\mathrm{~N})$ and the profit of the purchased $\mathrm{E}_{2}$ is $\mathrm{P}_{2}$ when there is an equilibrium with $\mathrm{n}$ players. After the "buy and close down" the profit of $E_{1}$ is $P_{1}(C D)$. After the "buy and manage" the profit of $E_{1}$ is $P_{1}$ (M).

Now one examines the three cases:

The "buy and close down" is chosen.

There are two conditions:

$\mathrm{P}_{1}(\mathrm{CD})>\mathrm{P}_{1}(\mathrm{~N})+\mathrm{P}_{2}$

meaning that E1 wins more after the "buy and close down" and when it had paid more than $\mathrm{P}_{2}$ to $\mathrm{E}_{2}$ and

$\mathrm{P}_{1}$

(CD)

$\mathrm{P}_{1}$

(2) meaning that $\mathrm{E} 1$ wins more having bought $\mathrm{E}_{2}$ if it closes down it than if it manages it. The close down is chosen if the conditions (1) and (2) are fulfilled: (1) means that $\mathrm{E}_{1}$ wins more by the close down than by selling the asset and (2) means that the close down gets more than the "keep and manage".

The "buy and manage" is chosen.

There are two conditions: 
$\begin{array}{llllllllll}\mathrm{P}_{1} & (\mathrm{M}) & & \mathrm{P}_{1} & (\mathrm{~N}) & + & \mathrm{P}_{2}\end{array}$

(3) meaning that E1wins more after the "buy and manage" and when it had paid for a price more than $\mathrm{P}_{2}$ to $\mathrm{E}_{2}$ and

$\mathrm{P}_{1}(\mathrm{M})>\mathrm{P}_{1}(\mathrm{CD})$

meaning that $\mathrm{E} 1$ wins more after having bought $\mathrm{E}_{2}$ if it manages it than if it closes down it. The "keep and manage" is chosen if the conditions (3) and (4) are fulfilled: (3) means that $\mathrm{E}_{1}$ wins more by the "keep and manage" than by demerging and (4) means that $E_{1}$ wins more by the "keep and manage" that by the close down.

No purchase.

There are two conditions:

$\mathrm{P}_{1}(\mathrm{M})<\mathrm{P}_{1}(\mathrm{~N})+\mathrm{P}_{2}$

meaning that E1 wins less after the "buy and manage" and when it had paid for a price more than $\mathrm{P}_{2}$ to $\mathrm{E}_{2}$, and

$\mathrm{P}_{1}(\mathrm{CD})<\mathrm{P}_{1}(\mathrm{~N})+\mathrm{P}_{2}$

meaning that E1wins less after the "buy and close down" and when it has paid for a price more than $\mathrm{P}_{2}$ to $E_{2}$. Therefore, there is no purchase. The demerging is chosen if the conditions (5) and (6) are fulfilled: (5) means that $\mathrm{E}_{1}$ wins more after the demerging and having got a little than $\mathrm{P}_{2}$, than if it manages the asset, and (6) means that $\mathrm{E}_{1}$ wins more after the demerging and having got a little than $\mathrm{P}_{2}$, than if it closes down the asset.

The choices can be shown in the Table 1 .

Table 1: the choices are shown. They depend on conditions. The asset can be not bought or already owned.

\begin{tabular}{|c|c|c|}
\hline & $\begin{array}{c}\text { The asset is to } \\
\text { buy }\end{array}$ & The asset is already owned \\
\hline $\begin{array}{ll}\mathrm{P}_{1}(\mathrm{CD})>\mathrm{P}_{1}(\mathrm{~N})+\mathrm{P}_{2} \\
\text { And } & \mathrm{P}_{1}(\mathrm{CD})>\mathrm{P}_{1} \\
& (\mathrm{M})\end{array}$ & $\begin{array}{l}\text { Buy and close } \\
\text { down }\end{array}$ & Close down \\
\hline $\begin{array}{c}\mathrm{P}_{1}(\mathrm{M})>\quad \mathrm{P}_{1}(\mathrm{~N})+\mathrm{P}_{2} \\
\text { And } \\
\mathrm{P} 1(\mathrm{M})>\mathrm{P}_{1}(\mathrm{CD})\end{array}$ & $\begin{array}{l}\text { Buy and } \\
\text { manage }\end{array}$ & Keep and manage \\
\hline $\begin{aligned} \mathrm{P}_{1}(\mathrm{CD}) & <\mathrm{P}_{1}(\mathrm{~N})+\mathrm{P}_{2} \\
& \text { And } \\
\mathrm{P}_{1}(\mathrm{M}) & <\mathrm{P}_{1}(\mathrm{~N})+\mathrm{P}_{2}\end{aligned}$ & No purchase & Demerging \\
\hline
\end{tabular}

There are tractable examples in the three cases.

Buy and close down: the example quoted in the preceding chapter is valid.

Buy and manage: suppose a cube of length 1 backed to the axis $0 \quad u_{1} u_{2} u_{3}$. The density is homogeneously distributed on the diagonals of the exterior sides. One is $(1,0,1),(1,1,0)$. Another is $(1,1,0),(0,1,1)$. The last is $(0,1,1),(1,0,1)$. The conditions (3) and (4) are fulfilled.

No purchase: to have an example of the condition (5) is difficult. Indeed, if one makes some general hypotheses, the merger is always profitable (in case of Bertrand competition). However, when the products are perfectly differentiated, the merger provides no gain. There is neither gain, neither loss. If one supposes that the asset is already owned, the example of "buy and close down" is valid for close down. The example of buy and manage is valid for keep and manage. The example for no purchase is valid for demerging.

The possibility of "buy and close down" which is profitable suggests to use it as a criterion for markets which are saturated with too many kinds of products. One could build up a software to know if products are enough differentiated or not. Thanks to market research one coarsely knows the density of utilities. Then one chooses a pace $\pi$ (for instance 0,1$)$ for the prices $p_{1}, p_{2}$ and $p_{3}\left(0 \leq p_{i} \leq 1\right)$. One calculates in every point $\left(p_{1}, p_{2}, p_{3}\right), D_{1}, D_{2}$ and $D_{3}$, then $P_{1}=p_{1} D_{1}, P_{2}=p_{2} D_{2}$ and $P_{3}=p_{3} D_{3}$. One determines the Nash equilibrium and the profits $P_{1 N}, P_{2 N}$, and $P_{3 N}$. In $\left(p_{1 N}, p_{2 N}, p_{3 N}\right)$ the profit $P_{i}$ does 
not change if the price $p_{i}$ varies to $p_{i N}+\pi$ or to $p_{i N}-\pi$. Then the density is projected on the plane $O u_{1}$ $\mathrm{u}_{2}\left(\mathrm{E}_{3}\right.$ is closed down). There is a Nash equilibrium with two players and the profits are $\mathrm{P}_{1 \mathrm{~N}}$ and $\mathrm{P}_{2 \mathrm{~N}}$. If $\mathrm{P}_{1 \mathrm{~N}}>\mathrm{P}_{1 \mathrm{~N}}+\mathrm{P}_{3 \mathrm{~N}}$ the "buy and close down" is profitable. If $\mathrm{P}_{1 \mathrm{~N}}<\mathrm{P}_{1 \mathrm{~N}}+\mathrm{P}_{3 \mathrm{~N}}$ the "buy and close down" is not profitable. Such a software could be of interest for banks or fintechs.

One can compare this criterion with those which are in the literature.

One finds in the literature two rival models, the Hotelling's model and the Salop's model:

The Hotelling' model.

When Hotelling published his article presenting the model in the 30s, it attracted attention [7]. It was a model on location and transport costs. On a segment $(0,1)$ of length 1 , the firms A and B choose their location in $\mathrm{x}=\mathrm{a}$ and $\mathrm{x}=1-\mathrm{b}(1-\mathrm{a}-\mathrm{b}<1)$. One can suppose than $\mathrm{A}$ is on the left and $\mathrm{B}$ on the right. There is a uniform density of consumers. The transport cost is $t f(d)>0, f$ increasing, where $d$ is the distance of the consumer in $x$ to the firm $A(d=|x-a|)$ or to the firm $B(d=|x-b|)$. But the model can also be used to study product differentiation [8]. The net utility of the good sold by $\mathrm{A}$ is $\mathrm{U}-$ $\mathrm{p}_{1}-\mathrm{t} \mathrm{f}(|\mathrm{x}-\mathrm{a}|)$ and the net utility of the good sold by B is $U-\mathrm{p}_{2}-\mathrm{t} f(|\mathrm{x}-\mathrm{b}|)$. If A and B are at the same point, one finds the Bertrand paradox $\left(\mathrm{p}_{1}=\mathrm{p}_{2}=\mathrm{c}, \Pi_{1}=\Pi_{2}=0\right)$. So not only the model can be used for location theory (New Palgrave Dictionary of Economics ${ }_{c}$, 2008) but it can be used to study the saturation of a market. In the first period of the game, the firms choose location and in the second period of the game they choose price. At the Nash equilibrium if the profits are less than the fees for entry the market is saturated (the products are not enough differentiated).

The results of the game can be presented [9]. First the function $\mathrm{f}$ cannot be linear: for some values of the locations, the Nash equilibrium of the second period game does not exist. Second, d'Aspremont and alii have demonstrated that if $\mathrm{f}$ is quadratic, Nash equilibrium exists [10]. The two firms locate at the ends of the segment (maximal differentiation). Again, if the profits are more than the fees for entry the market is not saturated, if they are less, it is saturated (an increase of $t$, meaning more product differentiation, could allow the entry being profitable).

One can compare the model to the criterium presented in the paper:

- In the Hotelling's model, there are only two firms. In the paper, three firms are considered, and possibly four, five ...

- In the model the consumers' tastes have exactly a particular shape ( $\mathrm{f}(\mathrm{d})=\mathrm{t} \mathrm{d}^{2}$ ). In the paper, the utilities have any shape. Market research allows knowing the cloud of utilities. The only constraint is that there is a unique Nash equilibrium (the computer finds it if it exists).

The Salop's model.

On a circle of length $1 \mathrm{n}$ firms locate. It is symmetrical [4]. The model allows to calculate the profits at the equilibrium. If they are more than the fees for entry the market is not saturated. If they are less, there are too many products (or more product differentiation should be allowed by an increase of the factor $t$, the cost being equal to $t d$ ). The model is interesting when the tastes of the consumers can be represented on a circle: a circular highway, times of departure of a plane, dates of festivities in some city during one year ...But concerning for instance telecommunications services, there is high or standard quality. The criterium presented in the paper requires no condition on the consumers' tastes.

Research continues thanks to two approaches:

The representative consumer approach.

There is a unique consumer whose utility function $\mathrm{U}(\mathrm{q})$ has some mathematical shape (q is a bundle of goods). The utility function is maximized by the consumer, given the choices made by the firms selling the goods.

The discrete points approach.

The points represent the tastes of the consumers. Some mathematical shape is chosen. The Hotelling's model and the Salop's model are examples of this approach. The criterium presented in the paper is also an example of this approach, bur no mathematical shape is supposed.

Finally, if the sector of telecommunications is concerned, the "buy and close down" which is profitable explains what occurs during a price war.

\section{Conclusion.}

In conclusion one can make two remarks, on the topic and on the method:

Remark on the topic.

One can explain the evolution of the sector of telecommunications in France between 2012 and 2108: 
- In 2012 there is the entry of Free, triggering a price war.

- In the following years, the reaction of the incumbents is to create low-cost operators which are their branches (Sosh, Red and BandYou).

- The price war is unbearable for the only virtual operator with a large size, Virgin Mobile. It is "bought and closed down". Indeed, since it was owned by SFR, it has been "closed down".

At the opposite, in Germany, Nederland and Denmark, the prices are low because of virtual operators with a large size and stable. There is no price war.

In the paragraph 4 is set out a model with two operators having networks, in competition, a low-cost operator and a virtual operator. One demonstrates that the "buy and close down" (the virtual operator is "bought and closed down") is profitable and chosen when there is a price war. It is also profitable and chosen when one passes from a Nash equilibrium (between the two operators) and another Nash equilibrium.

The topic is all the more interesting since the same could occur in Italy. Indeed, Free has created an operator in this country and has triggered a price war, like in France. Incumbents have created lowcost operators, Kena Mobile in the case of Telecom Italia, and Ho! Mobile in the case of Vodafone. A virtual operator with a large size which is threatened is Lycamobile (which has about 1 million customers).

Remark on the method.

In general, the "buy and close down" which is profitable is a criterium for products not enough differentiated (like in the Bertrand paradox). One can give examples. For instance, consider a cube of side 1 backed to the axes, with homogeneous density. The products are enough differentiated: the "buy and close down" is not profitable. But if the cube slides along the bisector on a distance $1 / 3$ (translation of vector $(1 / 3,1 / 3,1 / 3))$ the products are not enough differentiated and the "buy and close down" is profitable (fig. 4).

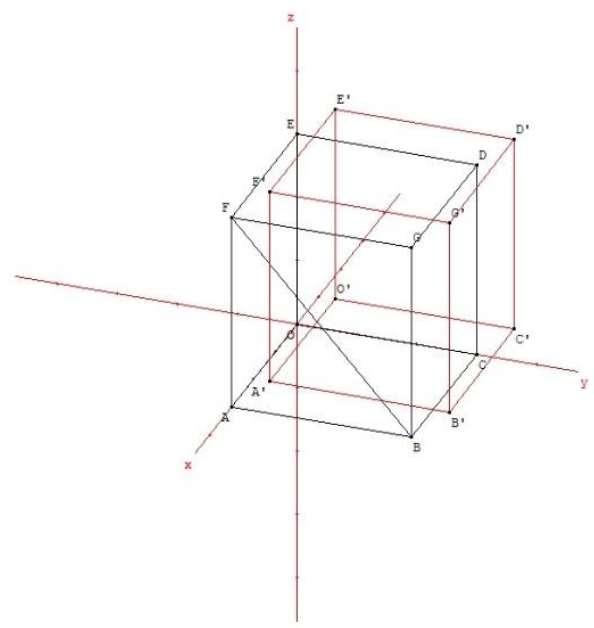

Figure 4: a cube is moved in a translation of vector $(1 / 3,1 / 3,1 / 3)$. The density is homogeneous.

Therefore, a software could be built up allowing to detect the markets with too many kinds of products. It could be useful for banks and fintechs.

One can give an intuitive and qualitative explanation. In case of "buy and close down" there is a negative direct effect: the buyer $E_{1}$ loses the profit $P_{2}$ of the bought firm $E_{2}$. Then there is a strong strategic effect. As the number of firms is $n-1$ and no more $n$, the profit of each firm increases. And concerning $\mathrm{E}_{1}$ the increase of its profit compensates and besides the loss due to the direct effect. Therefore, this increase of the profit is large. It proves that the market was saturated with too many kinds of products (since once there is a competitor less, the profit of a firm which remains active increases very much).

\section{References.}

[1] Encyclopediathefreedictionary.com Article: "Mobile Virtual Network Operator (MVNO)" 2019

[2] Encyclopediathefreedictionary.com Article: "Mobile Network Operator (MNO)" 2019 
[3] Wikipedia.fr Article: "Virgin Mobile" 2019

[4] J. Tirole "Théorie de l'organisation industrielle" ("Theory of industrial organization") Paris: Economica. 1995.

[5] O. Lefebvre "Game theory and the stakes in the telecommunications industry" Berlin: Lambert Academic Publishing 2014.

[6] Wikipedia.fr Article : UMP (entreprise) 2019

[7] New Palgrave Dictionary of Economics. Article: "Hotelling” Author: K. Arrow 2008.

[8] New Palgrave Dictionary of Economics. Article: "Location Theory" Author: S. Anderson 2008.

[9] New Palgrave Dictionary of Economics. Article: "Product Differentiation" Author: J. F. Thysse 2008.

[10] C. d'Aspremont, J. Gabszewisz, J. F. Thysse "On Hotelling's stability in competition" Econometrica Vol 47 p 1145 - 11501979. 